TITLE:

\title{
Investigation on origin of Z[1/2] center in SiC by deep level transient spectroscopy and electron paramagnetic resonance
}

\section{AUTHOR(S):}

Kawahara, Koutarou; Xuan Thang Trinh; Nguyen Tien Son; Janzen, Erik; Suda, Jun; Kimoto, Tsunenobu

\section{CITATION:}

Kawahara, Koutarou ... [et al]. Investigation on origin of Z[1/2] center in SiC by deep level transient spectroscopy and electron paramagnetic resonance. Applied Physics Letters 2013, 102(11): 112106.

\section{ISSUE DATE:}

2013-03-19

URL:

http://hdl.handle.net/2433/187953

\section{RIGHT:}

(C) 2013 American Institute of Physics. This article may be downloaded for personal use only. Any other use requires prior permission of the author and the American Institute of Physics. 


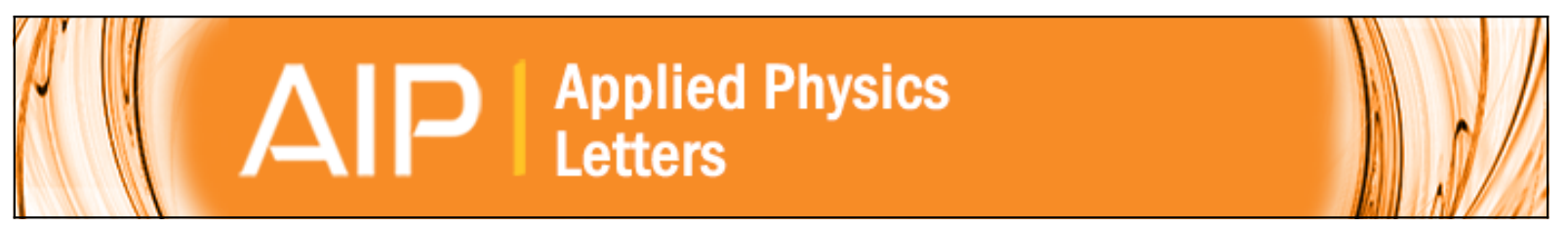

Investigation on origin of Z 1 / 2 center in SiC by deep level transient spectroscopy and electron paramagnetic resonance

Koutarou Kawahara, Xuan Thang Trinh, Nguyen Tien Son, Erik Janzén, Jun Suda, and Tsunenobu Kimoto

Citation: Applied Physics Letters 102, 112106 (2013); doi: 10.1063/1.4796141

View online: http://dx.doi.org/10.1063/1.4796141

View Table of Contents: http://scitation.aip.org/content/aip/journal/apl/102/11?ver=pdfcov

Published by the AIP Publishing

\section{Articles you may be interested in}

Resolving the $\mathrm{E} \mathrm{H} 6$ / 7 level in $4 \mathrm{H}$-SiC by Laplace-transform deep level transient spectroscopy

Appl. Phys. Lett. 102, 152108 (2013); 10.1063/1.4802248

Deep level defects in Si-doped Al x Ga 1 x N films grown by molecular-beam epitaxy

Appl. Phys. Lett. 86, 152109 (2005); 10.1063/1.1887817

Anomalous behaviors of E 1 E 2 deep level defects in $6 \mathrm{H}$ silicon carbide

Appl. Phys. Lett. 86, 031903 (2005); 10.1063/1.1853523

Formation of the Z 1,2 deep-level defects in $4 \mathrm{H}-\mathrm{SiC}$ epitaxial layers: Evidence for nitrogen participation

Appl. Phys. Lett. 81, 4841 (2002); 10.1063/1.1529314

Annealing behavior of vacancies and $\mathrm{Z} 1 / 2$ levels in electron-irradiated $4 \mathrm{H}-\mathrm{SiC}$ studied by positron annihilation and deep-level transient spectroscopy

Appl. Phys. Lett. 79, 3950 (2001); 10.1063/1.1426259

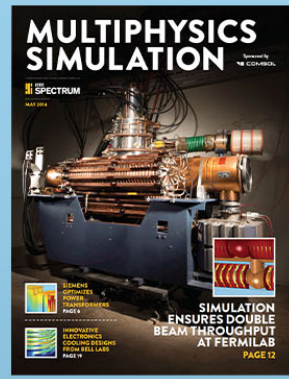

Free online magazine

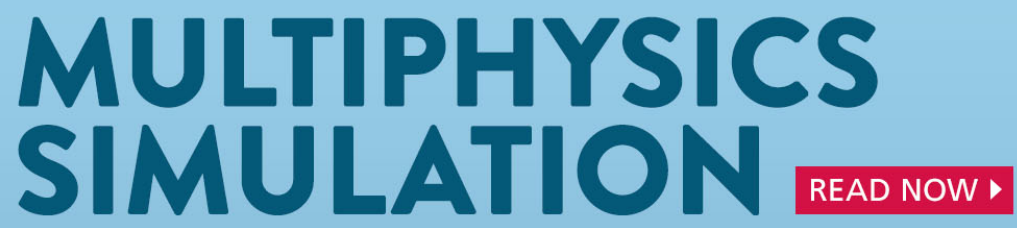




\title{
Investigation on origin of $\mathrm{Z}_{1 / 2}$ center in SiC by deep level transient spectroscopy and electron paramagnetic resonance
}

\author{
Koutarou Kawahara, ${ }^{1, a)}$ Xuan Thang Trinh, ${ }^{2}$ Nguyen Tien Son, ${ }^{2}$ Erik Janzén, ${ }^{2}$ Jun Suda, ${ }^{1}$ \\ and Tsunenobu Kimoto ${ }^{1, b)}$ \\ ${ }^{1}$ Department of Electronic Science and Engineering, Kyoto University, Katsura, Nishikyo, \\ Kyoto 615-8510, Japan \\ ${ }^{2}$ Department of Physics Chemistry and Biology, Linköping University, 58183 Linköping, Sweden
}

(Received 26 December 2012; accepted 8 March 2013; published online 19 March 2013)

\begin{abstract}
The $\mathrm{Z}_{1 / 2}$ center in n-type $4 \mathrm{H}$-SiC epilayers - a dominant deep level limiting the carrier lifetime-has been investigated. Using capacitance versus voltage $(C-V)$ measurements and deep level transient spectroscopy (DLTS), we show that the $Z_{1 / 2}$ center is responsible for the carrier compensation in n-type $4 \mathrm{H}$-SiC epilayers irradiated by low-energy $(250 \mathrm{keV})$ electrons. The concentration of the $\mathrm{Z}_{1 / 2}$ defect obtained by $C-V$ and DLTS correlates well with that of the carbon vacancy $\left(\mathrm{V}_{\mathrm{C}}\right)$ determined by electron paramagnetic resonance, suggesting that the $\mathrm{Z}_{1 / 2}$ deep level originates from $\mathrm{V}_{\mathrm{C}}$. (C) 2013 American Institute of Physics. [http://dx.doi.org/10.1063/1.4796141]
\end{abstract}

$\mathrm{SiC}$ is an attractive semiconductor for realizing highpower, high-temperature, and high-frequency devices. Deep levels in semiconductors can act either as carrier traps reducing the conductivity or recombination centers limiting the carrier lifetimes. The $\mathrm{Z}_{1 / 2}$ center $^{1-3}$ is one of the most important deep levels in $4 \mathrm{H}-\mathrm{SiC}$, known as a lifetime killer. ${ }^{4,5}$ The origin of the $Z_{1 / 2}$ center seems to include a carbon vacancy $\left(V_{C}\right)$ because (i) this defect is generated by irradiation with electrons of energy as low as $100 \mathrm{keV},{ }^{6-8}$ which corresponds to the threshold energy that can displace only carbon atoms in $\mathrm{SiC}$ and (ii) a lower $\mathrm{Z}_{1 / 2}$ concentration is observed in $\mathrm{SiC}$ epilayers grown under $\mathrm{C}$-rich condition. ${ }^{9}$

Based on the correlation between the energy determined by deep level transient spectroscopy (DLTS) for the $Z_{1 / 2}$ center and by electron paramagnetic resonance (EPR) for the single negative $\mathrm{C}$ vacancy $\left(\mathrm{V}_{\mathrm{C}}(-)\right),{ }^{10}$ the $\mathrm{Z}_{1 / 2}$ center has recently been suggested to be the acceptor level of $\mathrm{V}_{\mathrm{C}} .{ }^{11} \mathrm{In}$ this paper, we will show the correlation in concentration between the $Z_{1 / 2}$ defect (obtained by capacitance-voltage $(C-V)$ and DLTS) and $\mathrm{V}_{\mathrm{C}}$ (determined by EPR) in n-type $4 \mathrm{H}-\mathrm{SiC}$ irradiated by low-energy $(250 \mathrm{keV})$ electrons with various electron fluences.

A direct comparison of the defect concentration determined by DLTS (or $C$ - $V$ ) and by EPR is not easy. EPR measurements are suitable for relatively high defect concentrations $\left(>10^{12}\right.$ spins), which require high electron fluences to create. However, materials irradiated with high electron fluences often become highly resistive and are not suitable for DLTS and $C$ - $V$ measurements. Therefore, in previous studies, samples used for DLTS were irradiated with much lower electron fluences compared to samples used for EPR measurements. ${ }^{12}$ In this study, in order to be able to characterize the same samples in $C$ - $V$, DLTS, and EPR experiments, we chose $\mathrm{n}$-type thick $4 \mathrm{H}-\mathrm{SiC}$ epilayers with a relatively high $\mathrm{N}$ concentration $\left(N_{\mathrm{d}} \sim 1.6 \times 10^{17} \mathrm{~cm}^{-3}\right)$ so

\footnotetext{
${ }^{a)}$ Electronic mail: kawahara@semicon.kuee.kyoto-u.ac.jp.

${ }^{b)}$ Also at Photonics and Electronics Science and Engineering Center (PESEC), Kyoto University, Katsura Campus, Nishikyo-ku, Kyoto 615-8510, Japan.
}

that the materials can still be used for electrical measurements after irradiation with high electron fluences.

The starting materials are n-type $4 \mathrm{H}-\mathrm{SiC}$ epilayers (thickness: $\left.100 \mu \mathrm{m}, N_{\mathrm{d}}: 1.6 \times 10^{17} \mathrm{~cm}^{-3}\right)$. The epilayers were irradiated by $250 \mathrm{keV}$ electrons with different fluences: (A) $7.5 \times 10^{18} \mathrm{~cm}^{-2}$, (B) $7.2 \times 10^{18} \mathrm{~cm}^{-2}$, (C) $5.7 \times 10^{18} \mathrm{~cm}^{-2}$, (D) $4.3 \times 10^{18} \mathrm{~cm}^{-2}$, and (E) $3.1 \times 10^{18} \mathrm{~cm}^{-2}$. Ni/SiC Schottky structures have been made on the samples used for $C-V, I-V$, and DLTS measurements while the substrate of the other set of samples to be used for EPR was removed by mechanical polishing. For data sampling in all DLTS measurements, a period width of $0.205 \mathrm{~s}$ and a frequency of $1 \mathrm{MHz}$ were employed. In DLTS measurements, the reverse bias voltage was varied in the range of $0-100 \mathrm{~V}$, which corresponds to the monitored depth of about $100-800 \mathrm{~nm}$ in samples A-E. EPR measurements were performed on an X-band $(\sim 9.4 \mathrm{GHz})$ Bruker E500 spectrometer equipped with a continuous Heflow cryostat, allowing the sample temperature regulation in the range of 4-295K. In photoexcitation EPR (photo-EPR) experiments, a $200 \mathrm{~W}$ halogen lamp and appropriate optical filters were used for excitation.

Figure 1(a) shows the $C-V$ characteristics at room temperature (RT) obtained from $\mathrm{SiC}$ irradiated with different fluences. The capacitance of samples A-D is very small and almost constant independent of the bias voltage, indicating that these samples have a completely compensated region (CR) caused by electron capture of deep levels (these samples have a very thick depletion region even under $0 \mathrm{~V}$ bias). Figure 1(b) shows the dependence of the CR thickness $\left(d_{\mathrm{CR}}\right)$ on the electron fluence, which was derived from the equation: $d_{\mathrm{CR}}=\epsilon / C$, where $\epsilon$ the dielectric constant and $C$ the capacitance per unit area obtained from Fig. 1(a). Samples irradiated with a higher fluence show a thicker CR, indicating that deep levels are not uniformly distributed along the depth. Figure 2 shows depth profiles of the $Z_{1 / 2}$ center in lower doping $4 \mathrm{H}-\mathrm{SiC}$ epilayers $\left(N_{\mathrm{d}} \sim 1.6 \times 10^{15} \mathrm{~cm}^{-3}\right.$; initial $\mathrm{Z}_{1 / 2}$ concentration: $1.7 \times 10^{13} \mathrm{~cm}^{-3}$ ) after $250 \mathrm{keV}$ electron irradiation with various fluences $\left(3 \times 10^{15} \mathrm{~cm}^{-2}\right.$, $1 \times 10^{16} \mathrm{~cm}^{-2}$, and $2 \times 10^{16} \mathrm{~cm}^{-2}$ ). Because the $\mathrm{CR}$ region is formed where the trap concentration exceeds the doping 


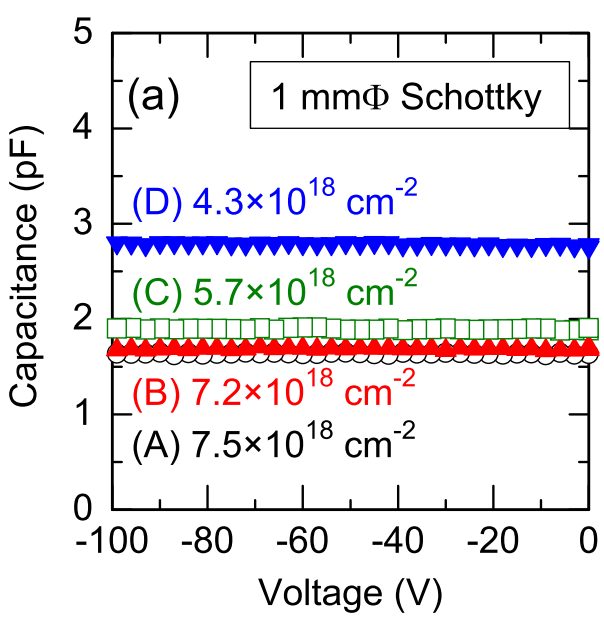

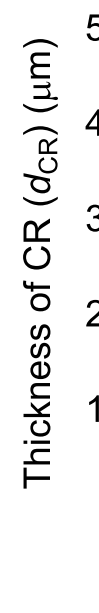

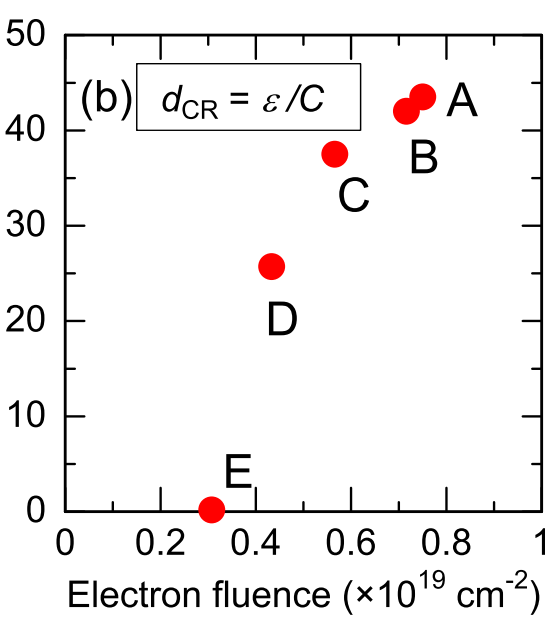

FIG. 1. (a) $C-V$ characteristics at RT of samples irradiated by low-energy $(250 \mathrm{keV})$ electrons with various fluences (circles: $7.5 \times 10^{18} \mathrm{~cm}^{-2}$, triangles: 7.2 $\times 10^{18} \mathrm{~cm}^{-2}$, squares: $5.7 \times 10^{18} \mathrm{~cm}^{-2}$, reverse triangles: $4.3 \times 10^{18} \mathrm{~cm}^{-2}$ ). (b) Thickness of the compensated region $\left(d_{\mathrm{CR}}\right)$ in samples A-E calculated from the constant capacitance shown in Fig. 1(a). concentration, a higher electron fluence should lead to a thicker $d_{\mathrm{CR}}$ as shown in Fig. 1(b).

Figure 3 shows DLTS spectra observed in samples A and $\mathrm{E}$. The spectrum in the lower temperature region of sample A was obtained by current deep level transient spectroscopy (I-DLTS) because the very low capacitance (caused by severe compensation) disturbed capacitance deep level transient spectroscopy (C-DLTS) measurements. At higher temperatures $(>400 \mathrm{~K})$, the capacitance recovered to the value before electron irradiation, which enabled C-DLTS measurements of irradiated samples. As shown in Fig. 3, ET1 $\left(E_{\mathrm{C}}-0.30 \mathrm{eV}\right){ }^{7} \mathrm{EH}_{1}\left(E_{\mathrm{C}}-0.34 \mathrm{eV}\right),{ }^{13}$ $\mathrm{Z}_{1 / 2}\left(E_{\mathrm{C}}-0.67 \mathrm{eV}\right),{ }^{1} \quad \mathrm{EH}_{3} \quad\left(E_{\mathrm{C}}-0.72 \mathrm{eV}\right),{ }^{13} \quad \mathrm{EH}_{5} \quad\left(E_{\mathrm{C}}\right.$ $-1.2 \mathrm{eV}),{ }^{13} \mathrm{ET} 4\left(E_{\mathrm{C}}-1.3 \mathrm{eV}\right)$, and $\mathrm{EH}_{6 / 7}\left(E_{\mathrm{C}}-1.5 \mathrm{eV}\right)^{13}$ centers were observed in the irradiated samples. The activation energy was derived with assuming a temperature independent capture cross section $(\sigma)$. Taking into account that the activation energy for $\sigma$ of $\mathrm{Z}_{1 / 2}$ center (which corresponds to the barrier for capturing the second electron to the $\mathrm{Z}_{1 / 2}$ level) is $0.074 \mathrm{eV},{ }^{14,15}$ the energy level of $\mathrm{Z}_{1 / 2}$ center is recalculated to be at $\sim E_{\mathrm{C}}-0.59 \mathrm{eV}$. All these deep levels are often observed in irradiated $4 \mathrm{H}-\mathrm{SiC}$ except for the ET4 center, which is not easy to be separated from the $\mathrm{EH}_{6 / 7}$ center because of severe overlapping. Among these centers, the $\mathrm{Z}_{1 / 2}$ center has the highest

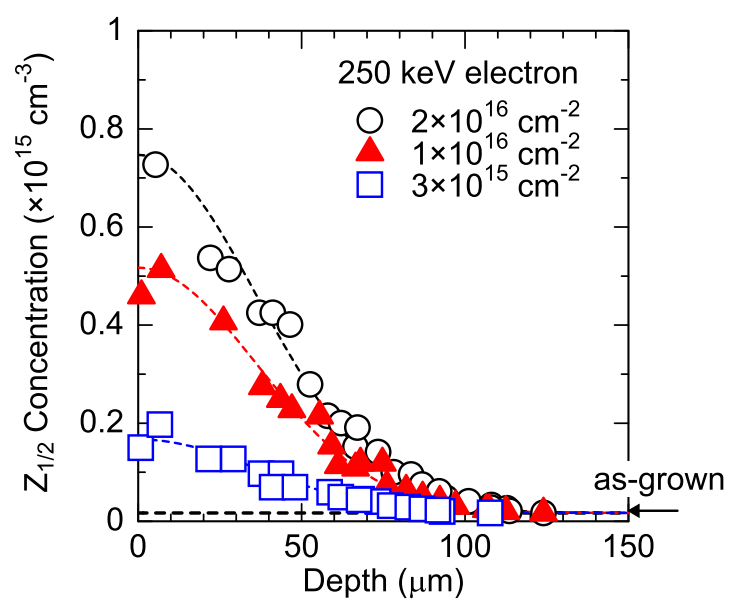

FIG. 2. Depth profiles of the $\mathrm{Z}_{1 / 2}$ center in low-doped $4 \mathrm{H}-\mathrm{SiC}$ epilayers $\left(N_{\mathrm{d}}: 1.6 \times 10^{15} \mathrm{~cm}^{-3}\right.$, initial $\mathrm{Z}_{1 / 2}$ concentration: $\left.1.7 \times 10^{13} \mathrm{~cm}^{-3}\right)$ after 250-keV-electron irradiation with various fluences (circles: $2 \times 10^{16} \mathrm{~cm}^{-2}$, triangles: $1 \times 10^{16} \mathrm{~cm}^{-2}$, squares: $3 \times 10^{15} \mathrm{~cm}^{-2}$ ). concentration although the absolute concentration could not be evaluated due to very high trap concentrations (the $\mathrm{Z}_{1 / 2}$ concentration in sample $\mathrm{E}$ is about $1 \times 10^{17} \mathrm{~cm}^{-3}$ while $N_{\mathrm{d}}$ is $1.6 \times 10^{17} \mathrm{~cm}^{-3}$ ).

Figure 4 shows the carrier concentration (filled circles) and the Fermi level (circles) in the CR of samples A-E. The carrier concentration $n$ in the $\mathrm{CR}$ was roughly estimated from the resistivity $\rho$ in the CR of each sample using the equation: $n=1 / e \rho \mu$. The $\rho$ value was calculated from the series resistance of Schottky barrier diodes $(R)$ obtained from $I-V$ measurements using the equation: $\rho=R / d_{\mathrm{CR}}$. The electron mobility $\mu$ in the CR was assumed to be $370 \mathrm{~cm}^{2} / \mathrm{Vs}$ using empirical equations given in a paper. ${ }^{16}$ For this estimation of $\mu$, an ionized impurity concentration of $3.2 \times 10^{17} \mathrm{~cm}^{-3}$ was used because there should be ionized donors of $1.6 \times 10^{17} \mathrm{~cm}^{-3}$ and traps filled with electrons of $1.6 \times 10^{17} \mathrm{~cm}^{-3}$. The Fermi level $E_{\mathrm{F}}$ in the $\mathrm{CR}$ can be estimated from the carrier concentration $n$ using the equation: $E_{\mathrm{F}}=E_{\mathrm{C}}-k T \ln \left(N_{\mathrm{C}} / n\right)$, and $E_{\mathrm{F}}$ is evaluated to be approximately at $E_{\mathrm{C}}-0.53 \mathrm{eV}$ in samples $\mathrm{A}-\mathrm{D}$, which is close to the energy level of the $Z_{1 / 2}$ center as shown in Fig. 4. With the Fermi level located at $E_{\mathrm{C}}-0.53 \mathrm{eV}$, the $\mathrm{Z}_{1 / 2}$ center $\left(E_{\mathrm{C}}-0.59 \mathrm{eV}\right)$ is occupied with electrons (the occupancy $\sim 91 \%$ at $300 \mathrm{~K}$ ). Taking into account that $\mathrm{Z}_{1 / 2}$ has the highest concentration (over $1 \times 10^{17} \mathrm{~cm}^{-3}$ ) among deep levels observed in these samples, this defect should be the dominant compensating center, creating the CR.

It has been shown that in darkness most of $\mathrm{V}_{\mathrm{C}}$ are in the double negative charge state, giving rise to no EPR signal. ${ }^{11}$ The observation of the EPR signal of $\mathrm{V}_{\mathrm{C}}(-)$ requires illumination. In all samples, the EPR signal of $\mathrm{V}_{\mathrm{C}}(-)$ is found to be dominant, suggesting that the acceptor levels of $\mathrm{V}_{\mathrm{C}}$ play a key role in the formation of the $\mathrm{CR}$ in studied samples. Figure 5 shows the dependence of the area density of $V_{C}(-)$ in the samples A-E obtained by EPR measurements under illumination with light of photon energy smaller than $1.6 \mathrm{eV}$, and the value $0.1 N_{\mathrm{d}} d_{\mathrm{CR}}$ on the electron fluence. It should be noted here that under illumination, $\mathrm{V}_{\mathrm{C}}$ can be in the neutral, single-negative, or double-negative charge state. ${ }^{11}$ The $\mathrm{V}_{\mathrm{C}}(-)$ volume density should be limited by $N_{\mathrm{d}}$ because an electron is needed for $\mathrm{V}_{\mathrm{C}}$ to become $\mathrm{V}_{\mathrm{C}}(-)$. The value $N_{\mathrm{d}} d_{\mathrm{CR}}$ corresponds to the maximum value of the $\mathrm{V}_{\mathrm{C}}(-)$ area density under an assumption that almost all $\mathrm{V}_{\mathrm{C}}(-)$ signal comes from the CR. The assumption is reasonable because 

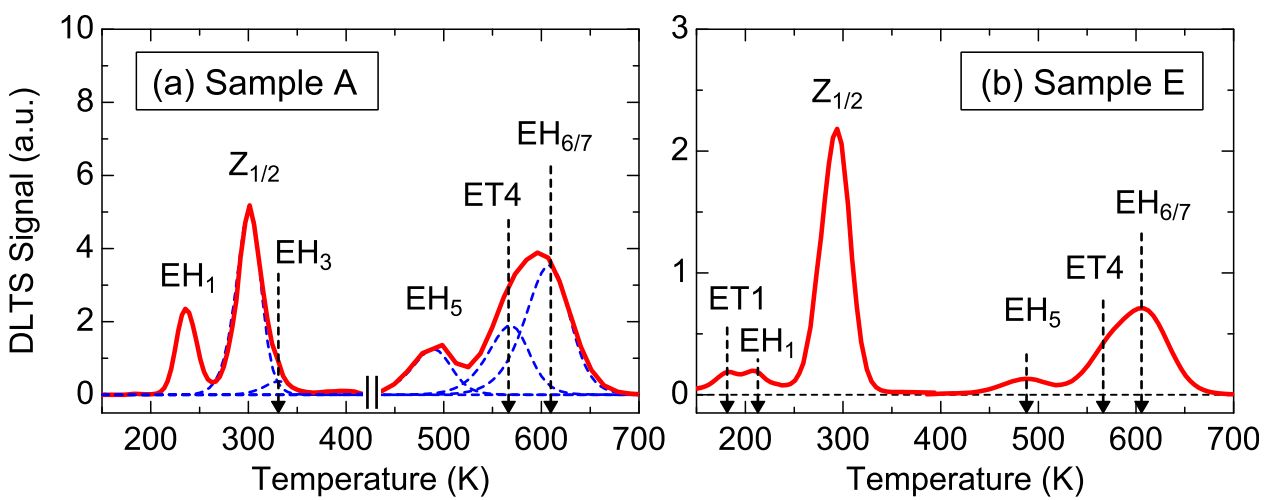

FIG. 3. DLTS spectra observed in samples (a) A (electron fluence: $7.5 \times 10^{18} \mathrm{~cm}^{-2}$ ) and (b) E (electron fluence: $3.1 \times 10^{18} \mathrm{~cm}^{-2}$ ). The lower temperature region of the spectrum in sample A was obtained by I-DLTS. the $\mathrm{V}_{\mathrm{C}}$ density in the $\mathrm{CR}$ is much higher than that in the tail uncompensated region, and most of $V_{C}$ in the tail region should be in the double-negative $(2-)$ charge state since the concentration of $\mathrm{V}_{\mathrm{C}}$ is lower than that of donor concentration and the Fermi level is near the $\mathrm{N}$ shallow donor. As shown in Fig. $5,10 \%$ of $N_{\mathrm{d}} d_{\mathrm{CR}}$ shows a good agreement with the

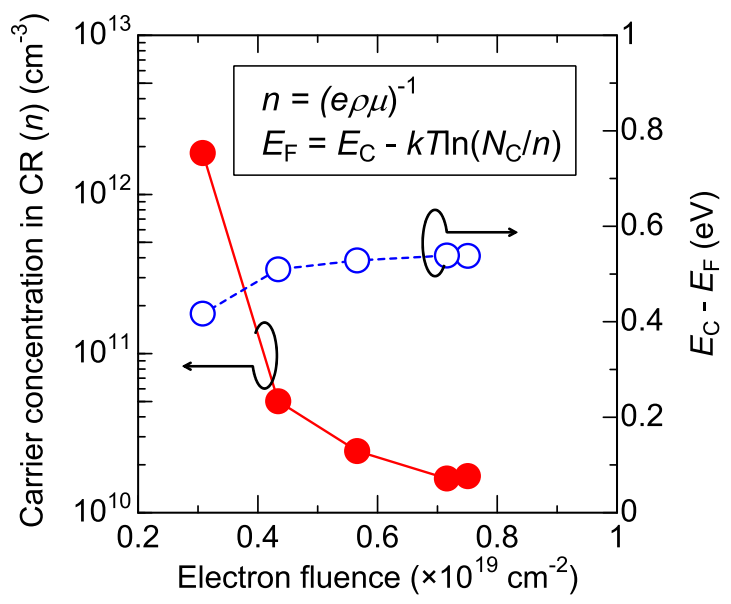

FIG. 4. The dependence on the electron fluence of the carrier concentration $n$ and the Fermi level at $300 \mathrm{~K}$ in the $\mathrm{CR}$ in samples A-E. Here, $n$ was estimated from the resistivity $\rho$ in the $\mathrm{CR}$ for each sample.

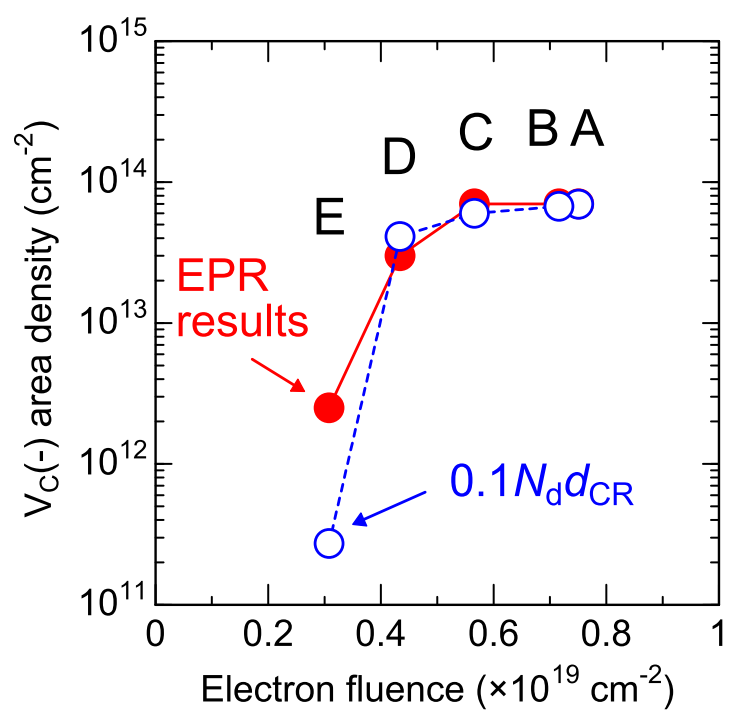

FIG. 5. Electron fluence dependence of the area density of carbon vacancy in the single-negative charge state $\left(\mathrm{V}_{\mathrm{C}}(-)\right)$ in samples $\mathrm{A}-\mathrm{E}$ obtained by EPR measurements under illumination with light of photon energy smaller than $1.6 \mathrm{eV}$, and the $0.1 N_{\mathrm{d}} d_{\mathrm{CR}}$ value. $N_{\mathrm{d}} d_{\mathrm{CR}}$ corresponds to the maximum $\mathrm{V}_{\mathrm{C}}(-)$ area density.
$\mathrm{V}_{\mathrm{C}}(-)$ area density obtained by EPR measurements, indicating that under illumination at $100 \mathrm{~K}$, about $10 \%$ of electrons in the CR exists as $\mathrm{V}_{\mathrm{C}}(-)$, while most of the other electrons may do as $\mathrm{V}_{\mathrm{C}}(2-)$. Note that the calculated value $0.1 N_{\mathrm{d}} d_{\mathrm{CR}}$ in the sample $\mathrm{E}$ is considerably smaller than the $\mathrm{V}_{\mathrm{C}}(-)$ area density obtained by EPR. Although the assumption that the EPR signal of $\mathrm{V}_{\mathrm{C}}(-)$ comes mainly from the $\mathrm{CR}$ is reasonable for samples A-D with thick CR, it is not valid for sample $E$, which has a very thin $C R$ and the amount of $V_{C}$ in the uncompensated region cannot be neglected compared to that in the very thin $\mathrm{CR}(\sim 0.17 \mu \mathrm{m})$. Neglecting the contribution of $\mathrm{V}_{\mathrm{C}}$ in the uncompensated region leads to the underestimation of the value $N_{\mathrm{d}} d_{\mathrm{CR}}$ in sample E. These EPR results with $\mathrm{V}_{\mathrm{C}}$ having the highest density among all defects in the samples $\mathrm{A}-\mathrm{E}$ and the $\mathrm{V}_{\mathrm{C}}(-)$ density following the maximum value of $\mathrm{V}_{\mathrm{C}}(-)$ density limited by $N_{\mathrm{d}}$ indicate that $\mathrm{V}_{\mathrm{C}}$ is the dominant defect creating the CR.

Comparing the data obtained from DLTS, $C-V$, and EPR measurements, it is clear that (i) the dominant deep level in samples $\mathrm{A}-\mathrm{E}$ is the $\mathrm{Z}_{1 / 2}$ center and the dominant point defect is $V_{C}$ and (ii) the compensation in irradiated samples is caused by electron capture to the $\mathrm{Z}_{1 / 2}$ center (as shown from DLTS) and to the acceptor levels of $V_{C}$ (as shown in EPR). Thus, the $\mathrm{Z}_{1 / 2}$ center, which capture two electrons as known from DLTS, ${ }^{14}$ should be related to the double negative charge state of $\mathrm{V}_{\mathrm{C}}$ (it is known that the $\mathrm{EH}_{7}$ DLTS level and

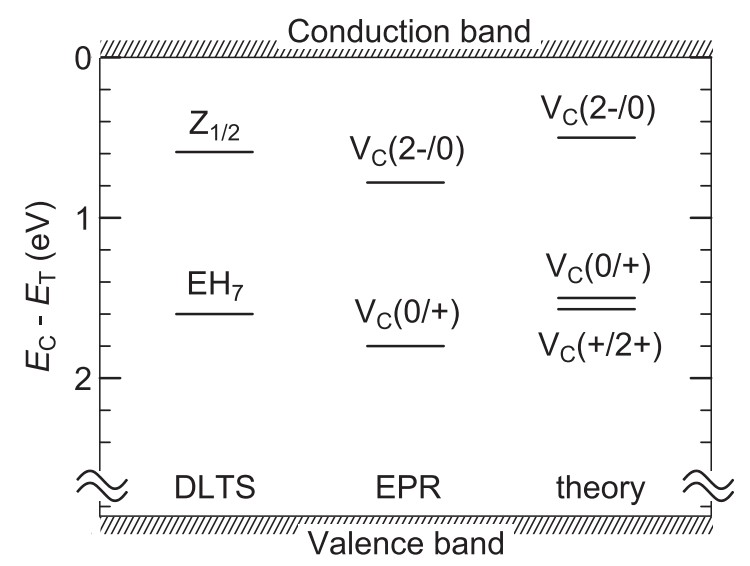

FIG. 6. Overview of the activation energy of deep levels obtained by DLTS (in this paper) and the energy of the $(2-/ 0)$ and $(0 /+)$ levels of $\mathrm{V}_{\mathrm{C}}$ determined by photo-EPR (Ref. 11) with respect to the conduction band minimum. The optical transitions determined by EPR involve a possible Franck-Condon shift, which has to be taken into account to be compared with the activation energy determined by DLTS. The energy levels of $V_{C}$ in different charge states obtained by ab initio calculation (Ref. 18) are also shown for comparison. 
the $\mathrm{Z}_{1 / 2}$ center originate from the same defect, ${ }^{7,17}$ and $\mathrm{EH}_{7}$ is related to the $(0 /+)$ charge state of $\mathrm{V}_{\mathrm{C}}$ (Ref. 11)).

Figure 6 shows the activation energy $\left(E_{\text {act }}\right)$ of deep levels obtained by DLTS and the optical transition levels related to $\mathrm{V}_{\mathrm{C}}$ levels $\left(E_{\mathrm{exc}}\right)$ determined by photo-EPR ${ }^{11}$ with respect to the conduction band edge $\left(E_{\mathrm{C}}=0\right)$. To compare $E_{\text {exc }}$ with $E_{\text {act }}$, a possible Franck-Condon shift involved in the optical transitions has to be taken into account $\left(E_{\mathrm{act}}=E_{\mathrm{exc}}-E_{\mathrm{FC}}\right)$. The activation energy of $\mathrm{V}_{\mathrm{C}}$ obtained by ab initio calculations ${ }^{18}$ are also shown in Fig. 6, which agrees well with the energy levels obtained by DLTS and EPR measurements.

In summary, using n-type $4 \mathrm{H}-\mathrm{SiC}$ epitaxial layers irradiated by low-energy $(250 \mathrm{keV})$ electrons, which can mainly create defects in the $\mathrm{C}$ sub-lattice $\left(\mathrm{V}_{\mathrm{C}}, \mathrm{C}\right.$ interstitials and their associated defects) with different fluences, we were able to employ different techniques ( $C$ - $V$, DLTS, and EPR) to study the $Z_{1 / 2}$ and $V_{C}$ defects in the same samples. It has been shown that $Z_{1 / 2}$ and $V_{C}$ are the dominant defects responsible for the carrier compensation observed in the irradiated samples, suggesting that the $\mathrm{Z}_{1 / 2}$ center originates from a $\mathrm{C}$ vacancy and is related to the EPR inactive 2 - charge state of $\mathrm{V}_{\mathrm{C}}$.

Support by the Grant-in-Aid for Scientific Research (21226008 and 80225078) from the Japan Society for the Promotion of Science, the Swedish Energy Agency, the Swedish Research Council VR/Linné LiLI-NFM, and the Knut and Alice Wallenberg Foundation is gratefully acknowledged.
${ }^{1}$ T. Dalibor, G. Pensl, H. Matsunami, T. Kimoto, W. J. Choyke, A. Schöner, and N. Nordell, Phys. Status Solidi A 162, 199 (1997).

${ }^{2}$ M. Weidner, T. Frank, G. Pensl, A. Kawasuso, H. Itoh, and R. KrauseRehberg, Physica B 308-310, 633 (2001).

${ }^{3}$ M. L. David, G. Alfieri, E. M. Monakhov, A. Hallén, C. Blanchard, B. G. Svensson, and J. F. Barbot, J. Appl. Phys. 95, 4728 (2004).

${ }^{4}$ P. B. Klein, B. V. Shanabrook, S. W. Huh, A. Y. Polyakov, M. Skowronski, J. J. Sumakeris, and M. J. O’Loughlin, Appl. Phys. Lett. 88, 052110 (2006).

${ }^{5}$ K. Danno, D. Nakamura, and T. Kimoto, Appl. Phys. Lett. 90, 202109 (2007).

${ }^{6}$ L. Storasta, J. P. Bergman, E. Janzén, A. Henry, and J. Lu, J. Appl. Phys. 96, 4909 (2004).

${ }^{7}$ K. Danno and T. Kimoto, J. Appl. Phys. 100, 113728 (2006).

${ }^{8}$ H. Kaneko and T. Kimoto, Appl. Phys. Lett. 98, 262106 (2011).

${ }^{9}$ T. Kimoto, S. Nakazawa, K. Hashimoto, and H. Matsunami, Appl. Phys. Lett. 79, 2761 (2001).

${ }^{10}$ T. Umeda, Y. Ishitsuka, J. Isoya, N. T. Son, E. Janzén, N. Morishita, T. Ohshima, H. Itoh, and A. Gali, Phys. Rev. B 71, 193202 (2005).

${ }^{11}$ N. T. Son, X. T. Trinh, L. S. Løvlie, B. G. Svensson, K. Kawahara, J. Suda, T. Kimoto, T. Umeda, J. Isoya, T. Makino, T. Ohshima, and E. Janzén, Phys. Rev. Lett. 109, 187603 (2012).

${ }^{12}$ P. Carlsson, N. Son, F. Beyer, H. Pedersen, J. Isoya, N. Morishita, T. Ohshima, and E. Janzén, Phys. Status Solidi (RRL) 3, 121 (2009).

${ }^{13}$ C. Hemmingsson, N. T. Son, O. Kordina, J. P. Bergman, E. Janzén, J. L. Lindström, S. Savage, and N. Nordell, J. Appl. Phys. 81, 6155 (1997).

${ }^{14}$ C. G. Hemmingsson, N. T. Son, A. Ellison, J. Zhang, and E. Janzén, Phys. Rev. B 58, R10119 (1998); 59, 7768 (1999).

${ }^{15}$ T. Kimoto, T. Yamamoto, Z. Y. Chen, H. Yano, and H. Matsunami, J. Appl. Phys. 89, 6105 (2001).

${ }^{16}$ S. Kagamihara, H. Matsuura, T. Hatakeyama, T. Watanabe, M. Kushibe, T. Shinohe, and K. Arai, J. Appl. Phys. 96, 5601 (2004).

${ }^{17}$ S. Sasaki, K. Kawahara, G. Feng, G. Alfieri, and T. Kimoto, J. Appl. Phys. 109, 013705 (2011).

${ }^{18}$ T. Hornos, A. Gali, and B. G. Svensson, Mater. Sci. Forum 679-680, 261 (2011). 